
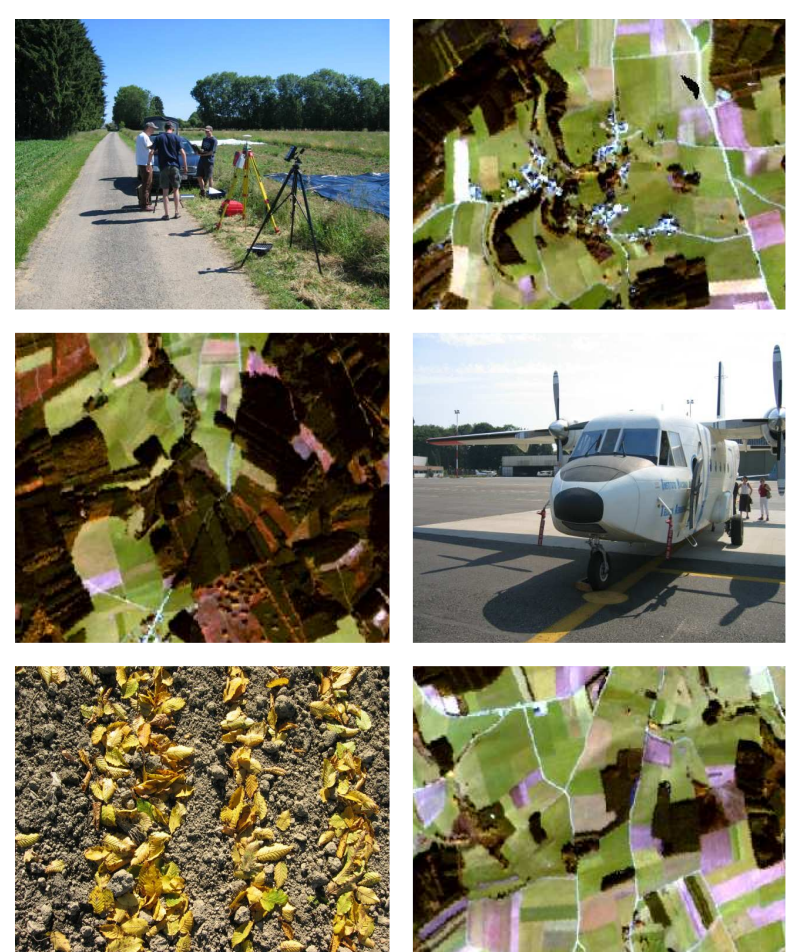
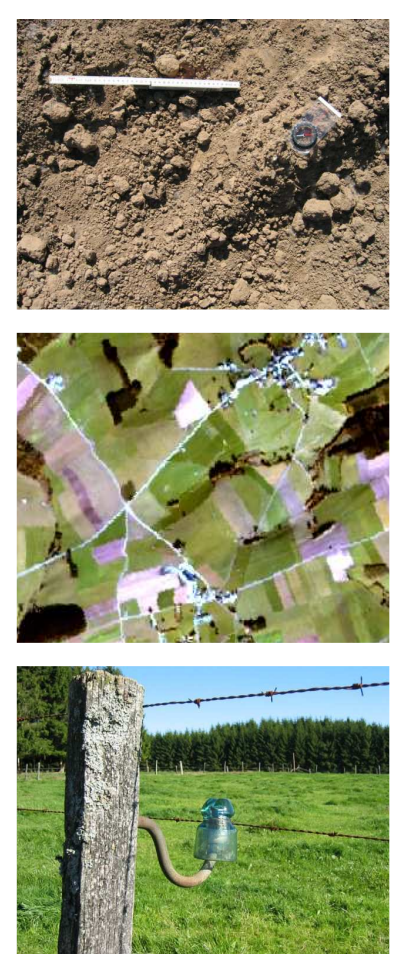

\title{
Laboratory, field and airborne spectroscopy for monitoring organic carbon content in agricultural soils
}

A. Stevens, B. van Wesemael,

B. Tychon, D. Rosillon, H. Bartholomeus, E. Ben Dor

UCL Université catholique de Louvain

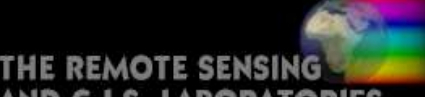
DÉPARTEMENT DE GÉOGRAPHIE 
- Introduction

- Why SOC monitoring?

- Why using reflectance spectroscopy?

- High spatial variability of $\mathrm{SOC} \rightarrow$ high sampling density reQuired

- Traditional sampling technioues are time consuming

- High potential for rapid in situ measurements and SOC mapping 


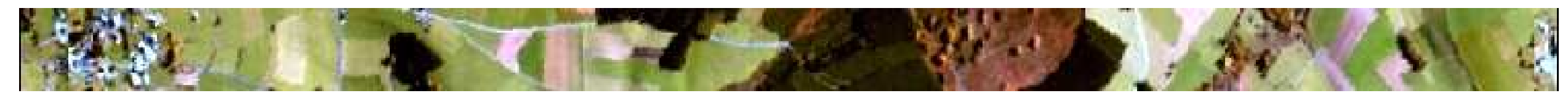

- Introduction

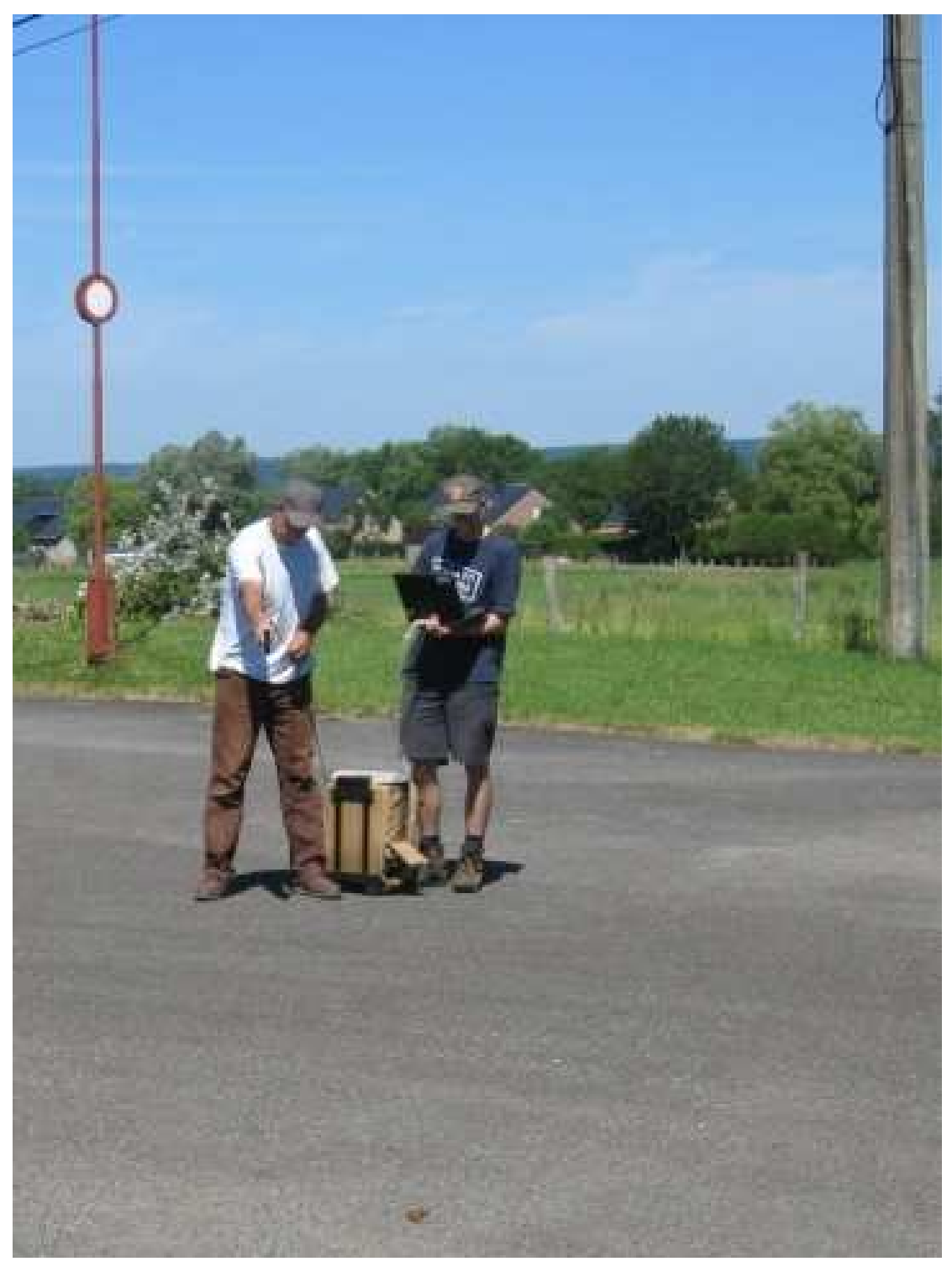

Hé LioSPIR, 25-26 0ctobre 2007 - GrenOble, France 
- Introduction

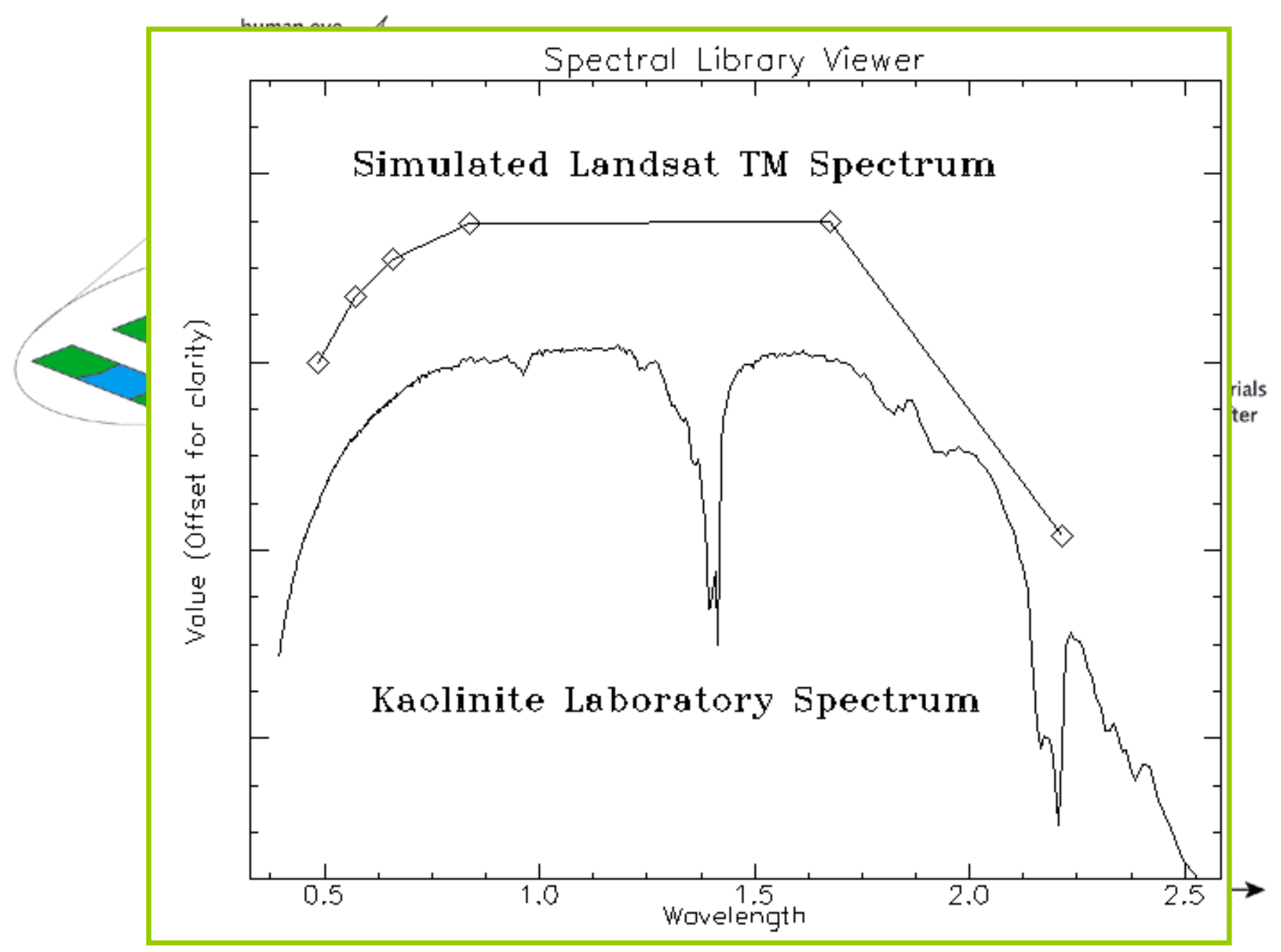

HÉlioSPIR, 25-26 0ctobre 2007 - GRenOble, FranCe 
- Introduction

- Objectives

- Compare the predictive ability of these three types of sensors for SOC determination using Partial Least Souare Regressions

- Evaluate the stability of calibrations

- Evaluate the potentialities for SOC monitoring and mapping 
- Methodology

- Study areas

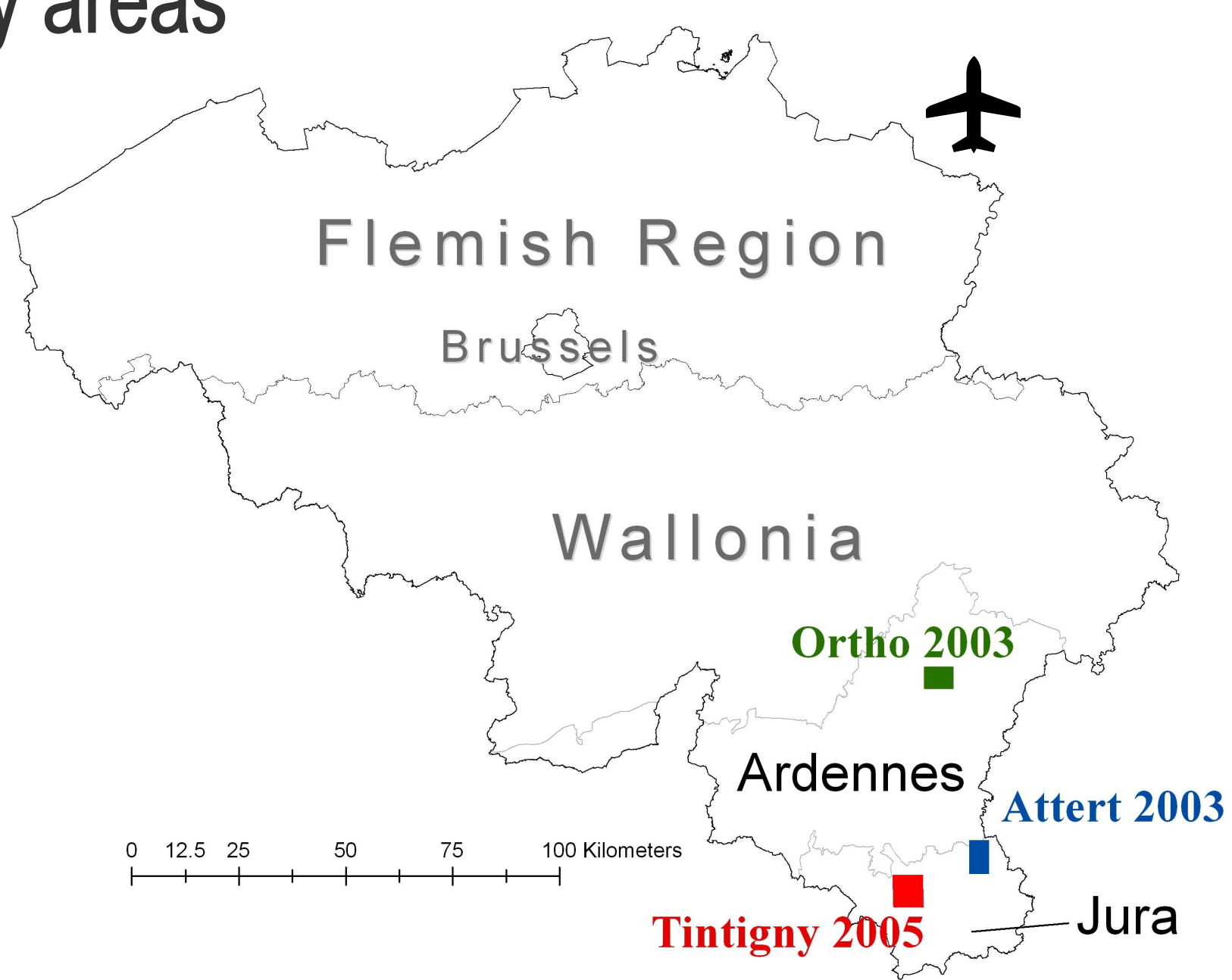

HÉLIOSPIR, 25-26 0ctobre 2007 - GRenOBLe, FranCE 


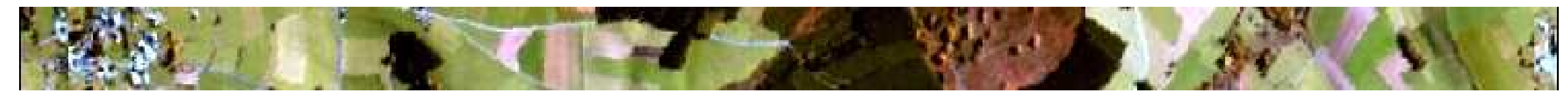

- Methodology

- Spectral measurements



HÉlioSPIR, 25-26 0ctobre 2007 - GRenOble, France 
- Methodology

- Portable Spectroscopy: Analytical Spectral Device (ASD: 350-2500 nm)

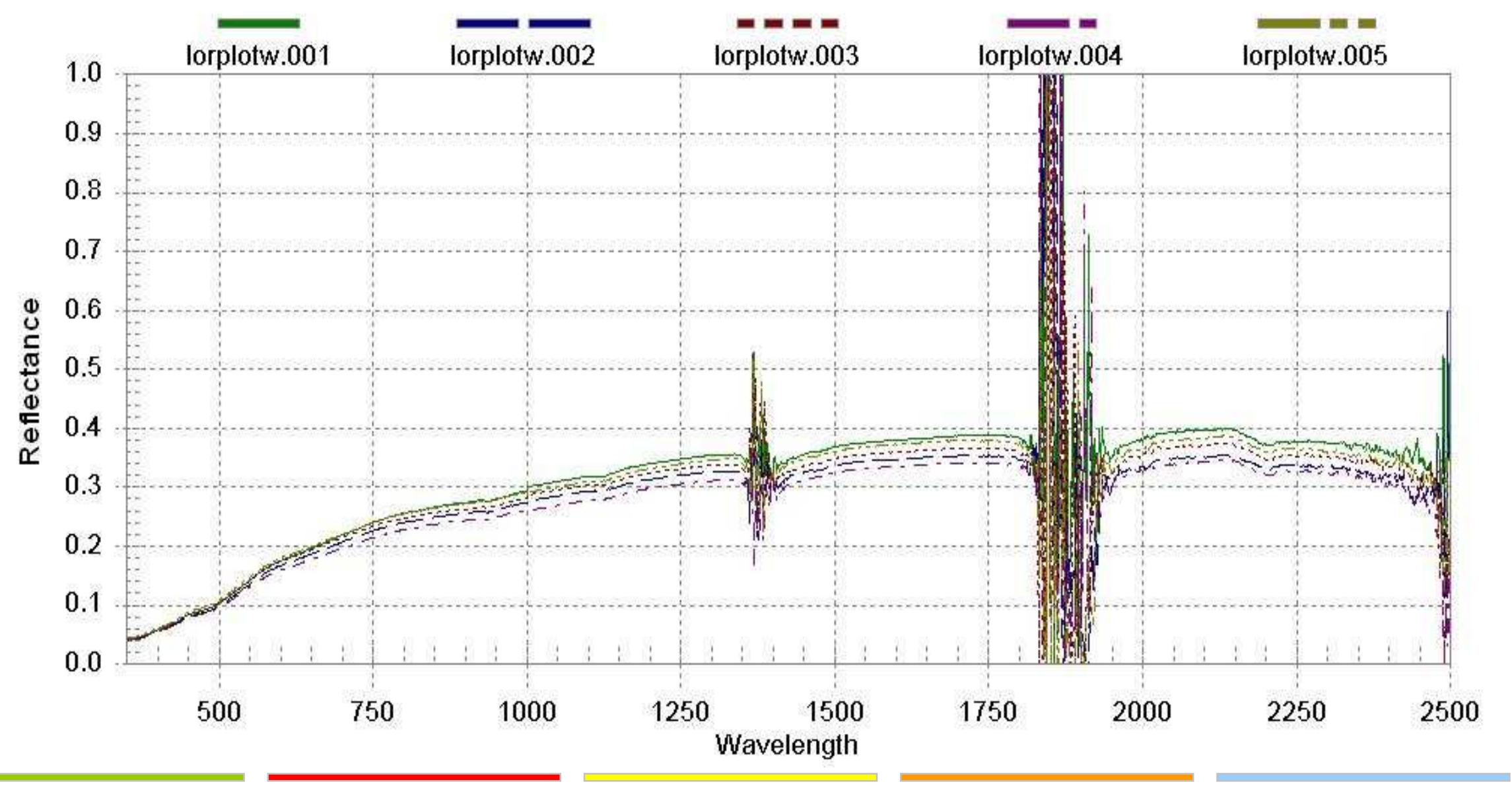

Hé LioSPIR, 25-26 0ctobre 2007 - GrenOble, France 
- Methodology

- Laboratory spectroscopy: spectral measurement of sieved $(2 \mathrm{~mm})$ and air-dried soil samples with the ASD contact probe

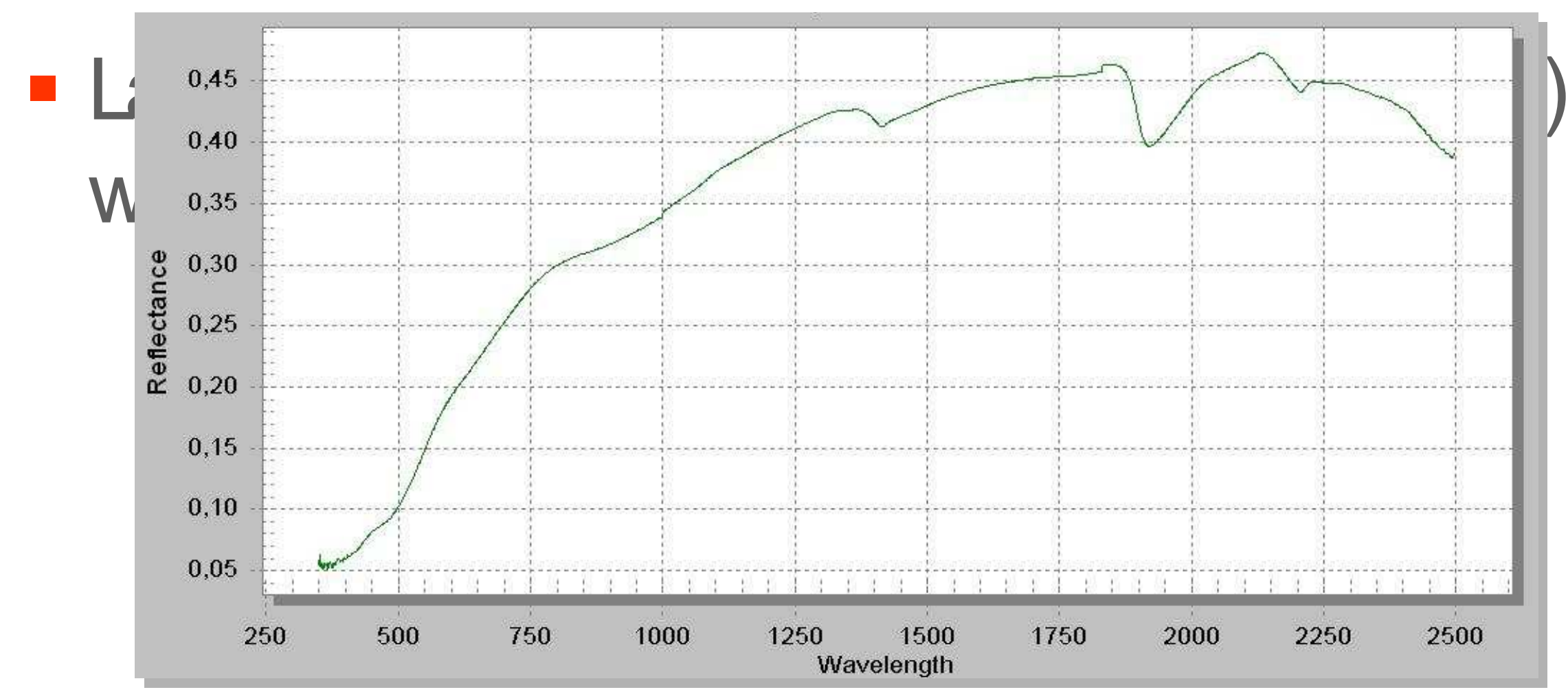

Hél i oSPI R, 25-26 Oct obr e 2007 - Grenobl e, Fr ance 
- Methodology

- Data transformation before statistical analysis

- Removing vegetation influence (spectra having a NDV >0.3)

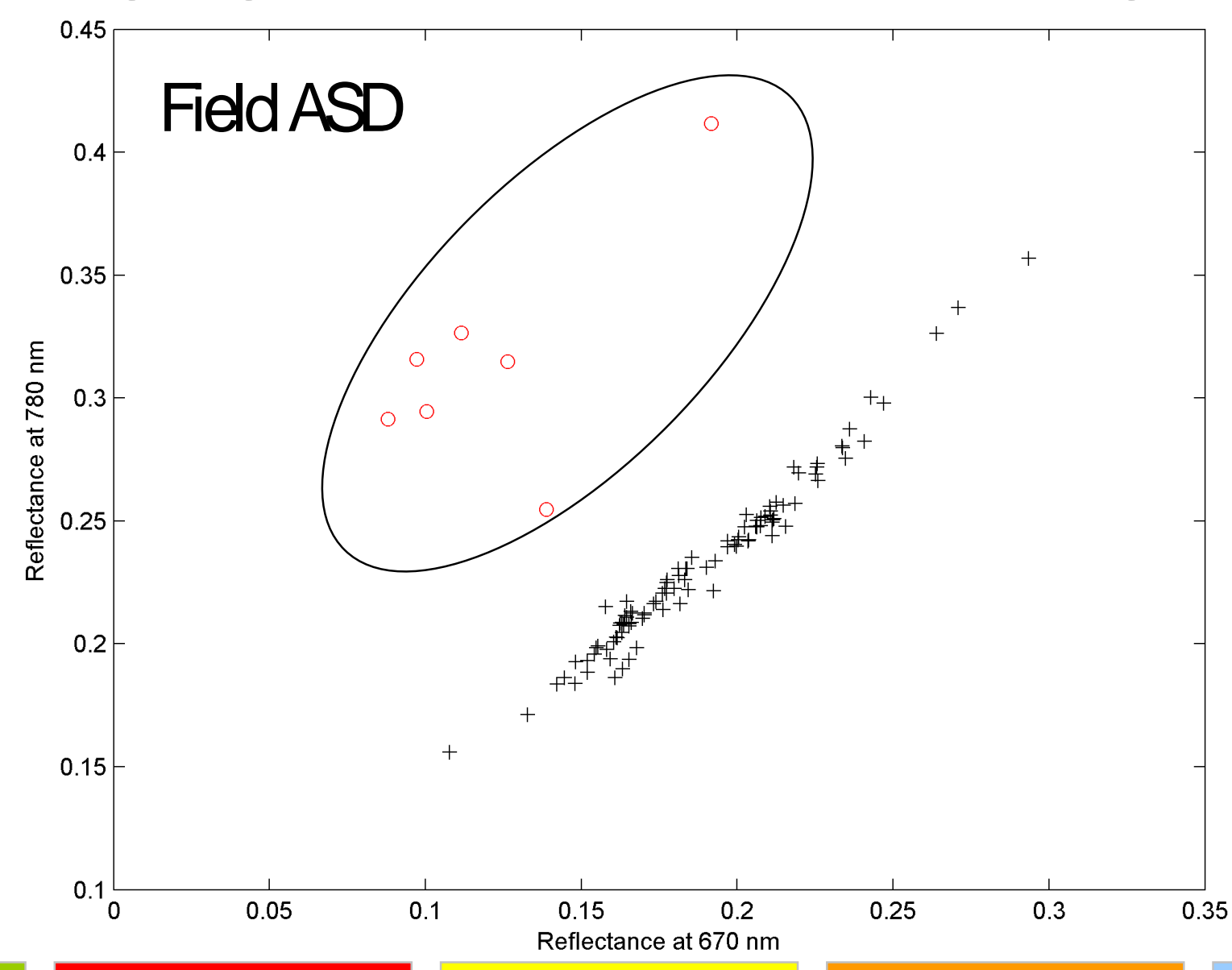

Hél i oSPI R, 25-26 Cot obr e 2007 - Grenobl e, Fr ance 
- Methodology

- Data transformation before statistical analysis
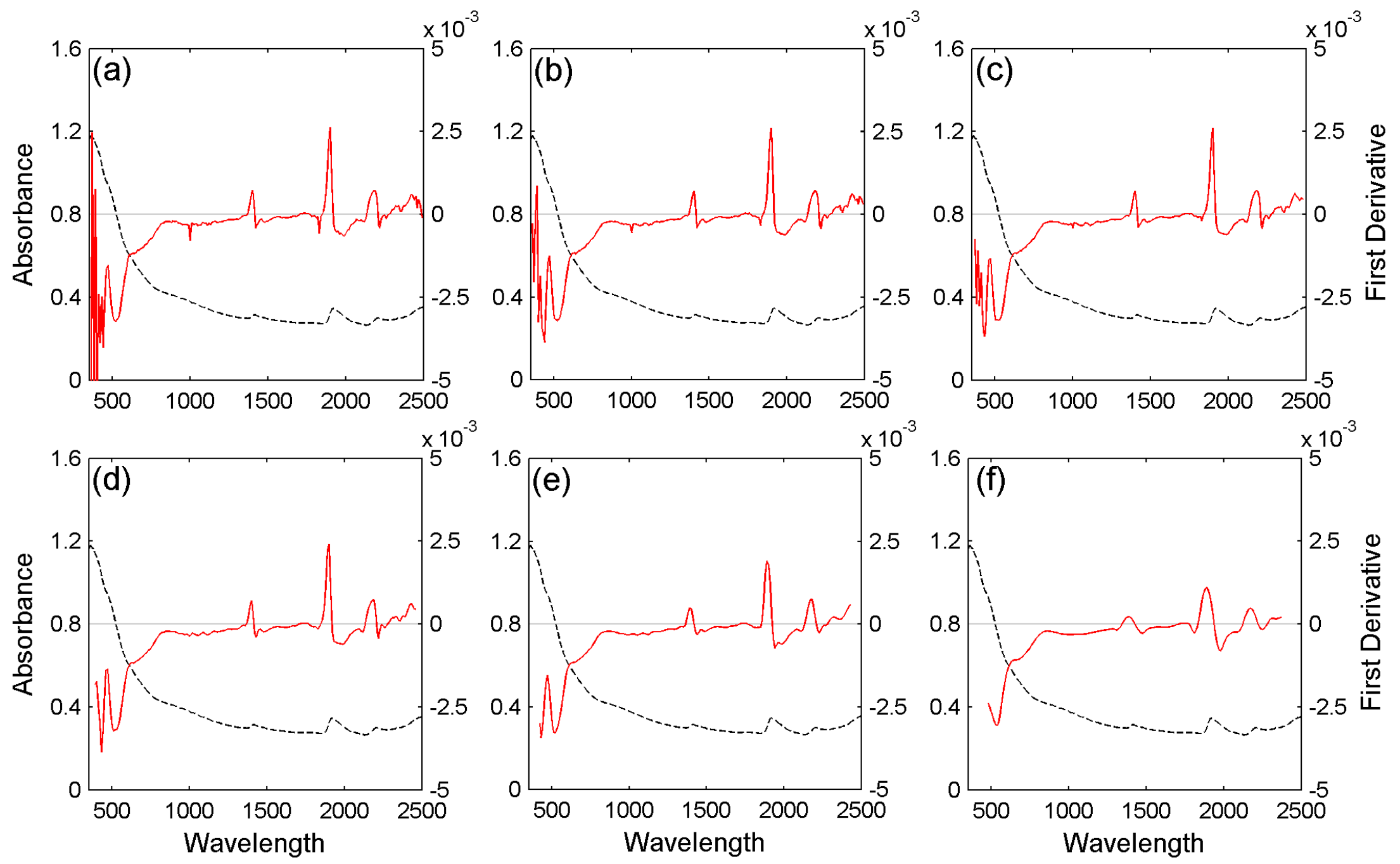

Hél i oSPI R, 25-26 Oct obr e2007 - Grenobl e, Fr ance 
Methodology

- Relate SOC and spectra using Partial Least Square Regressions (PLSR)

- Select the best model (pretreatment) on the basis of their Ratio of Performance to Deviation (=RMSEP / SD)

- To test the stability of the calibrations, we joined current ASD field measurements with those of previous campaigns (CASI 2003) producing a dataset of 201 samples with varying carbon content, texture, soil surface condition and soil types 
- Results
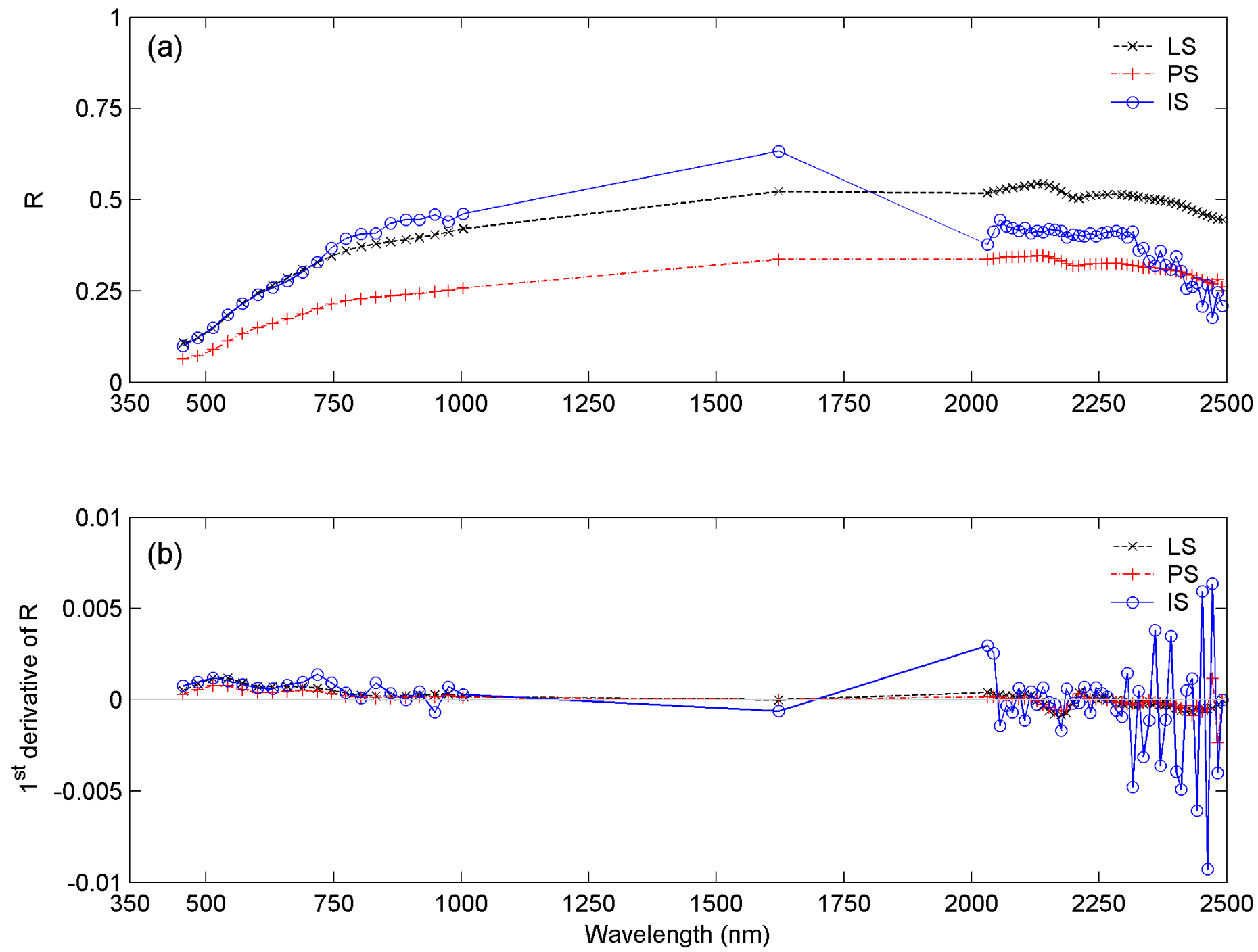

Hél i oSPI R, 25-26 Oct obr e2007 - Grenobl e, Fr ance 


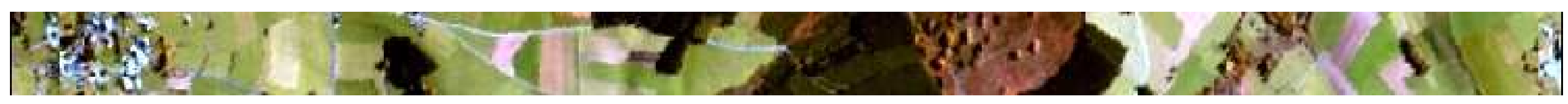

- Results
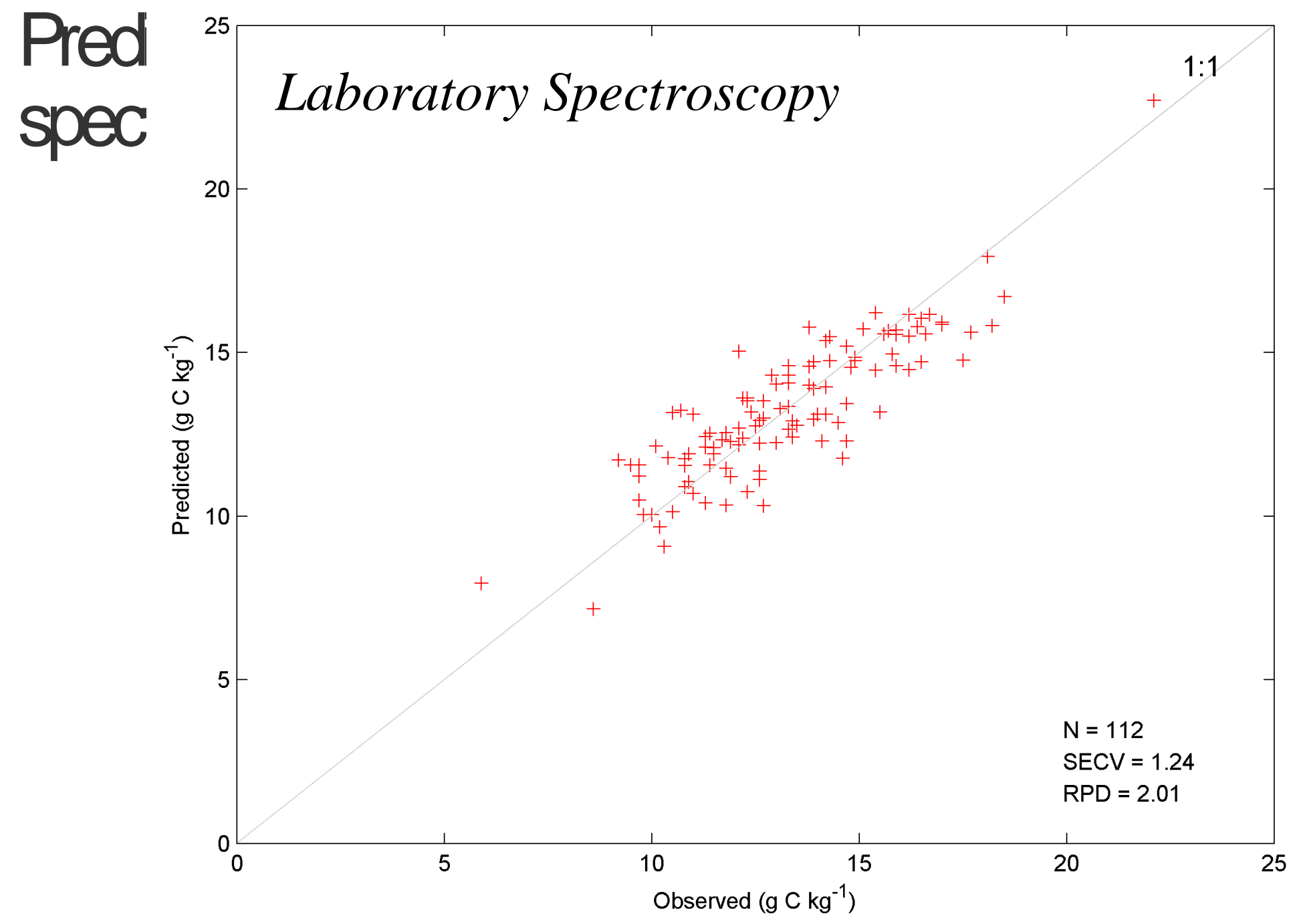

NIR

Hél i oSPI R, 25-26 Oct obr e2007 - Grenobl e, Fr ance 
Results

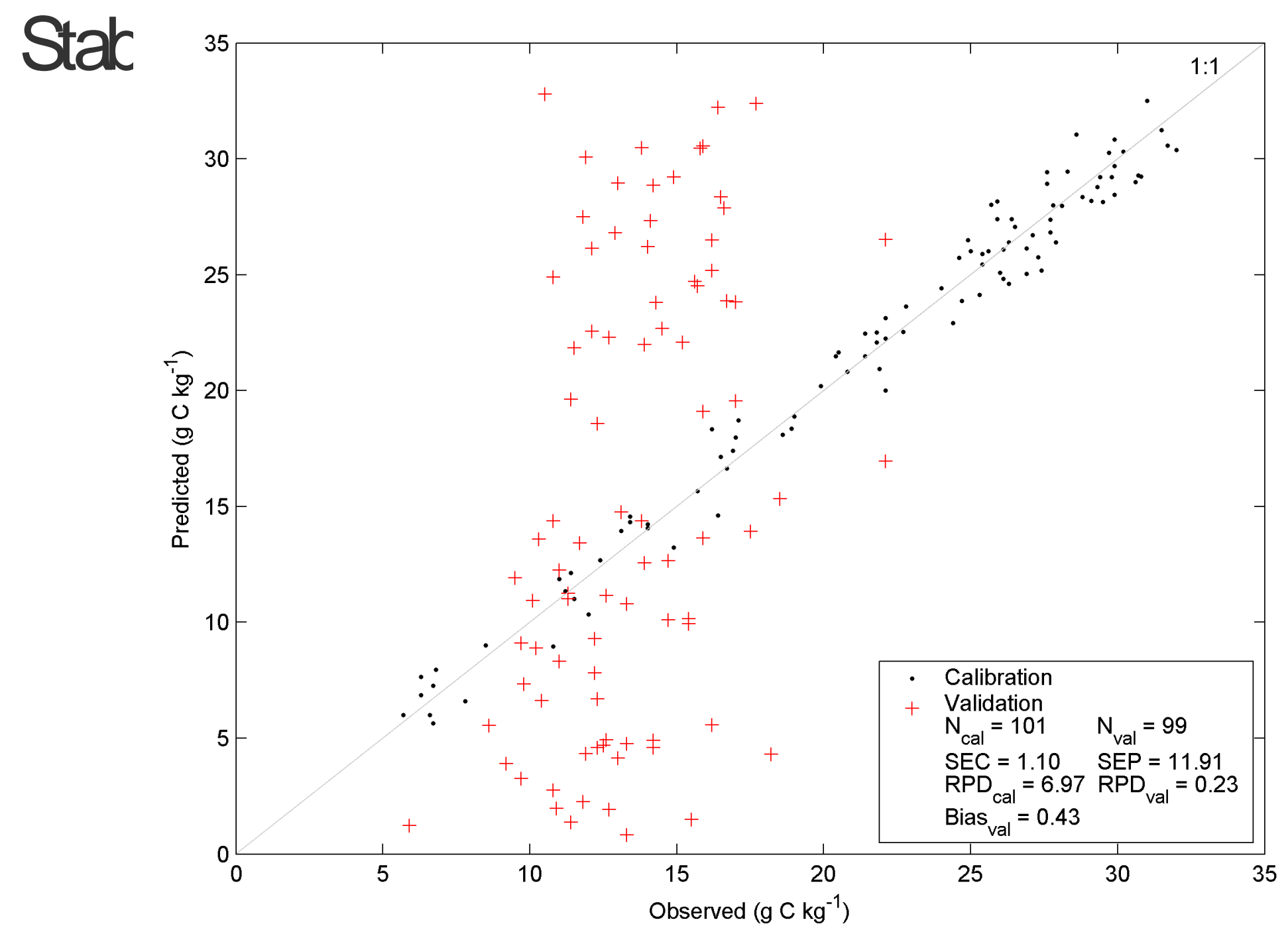

Hél i oSPI R, 25-26 Oct obr e2007 - Grenobl e, Fr ance 
- Results

\section{Stability across time and space: cross validation}

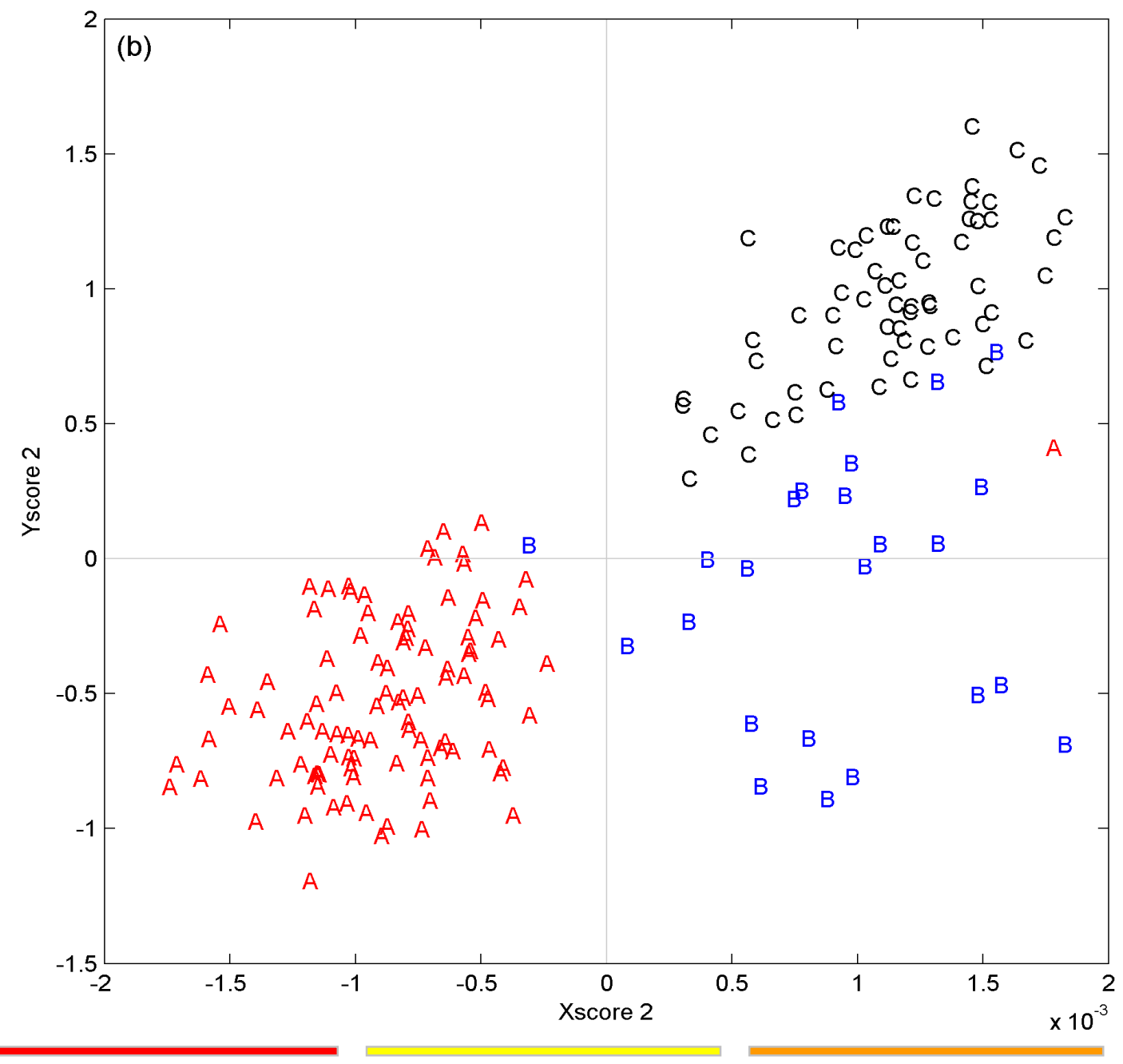

Hél i oSPI R, 25-26 Cot obr e2007 - Grenobl e, Fr ance 
- Results

- Summary of results

- There is a decrease in predictive ability from laboratory spectroscopy to remote-sensing due to:

- Difference in sensor characteristics (number of spectral bands);

- Uncontrolled measuring conditions (light source quality, soil surface conditions)

- The ASD gives accuracies $( \pm 0.1 \% \mathrm{C})$ that are similar to a routine analytical method (Walkley\&Black)

- Calibrations are currently site-specific and partly fail to predict, under a proper independent validation, samples belonging to another study area 
Results

\section{Summary of results}

- Further needs:

- More measurements (spectral libraries)!

- Standard spectral measurement protocols in the field (surface conditions required,etc.) 
- - - Soil Monitoring

- Mbnitoring of soil carbon

- Why WNR spectroscopy offers a great potential in the context of soil monitoring?

- Minimal Detectable Difference (MDD) : How many samples are required to demonstrate a given change in SOC stocks?

- SOC stock change after management change are $<=2$ C Cha $^{-1} \mathrm{y}^{-1}$ (Freibauer et al., 2004)

- After 3-5 year, it corresponds to + or - 5 tC $^{-1}{ }^{-1}$ 
Soil Monitoring

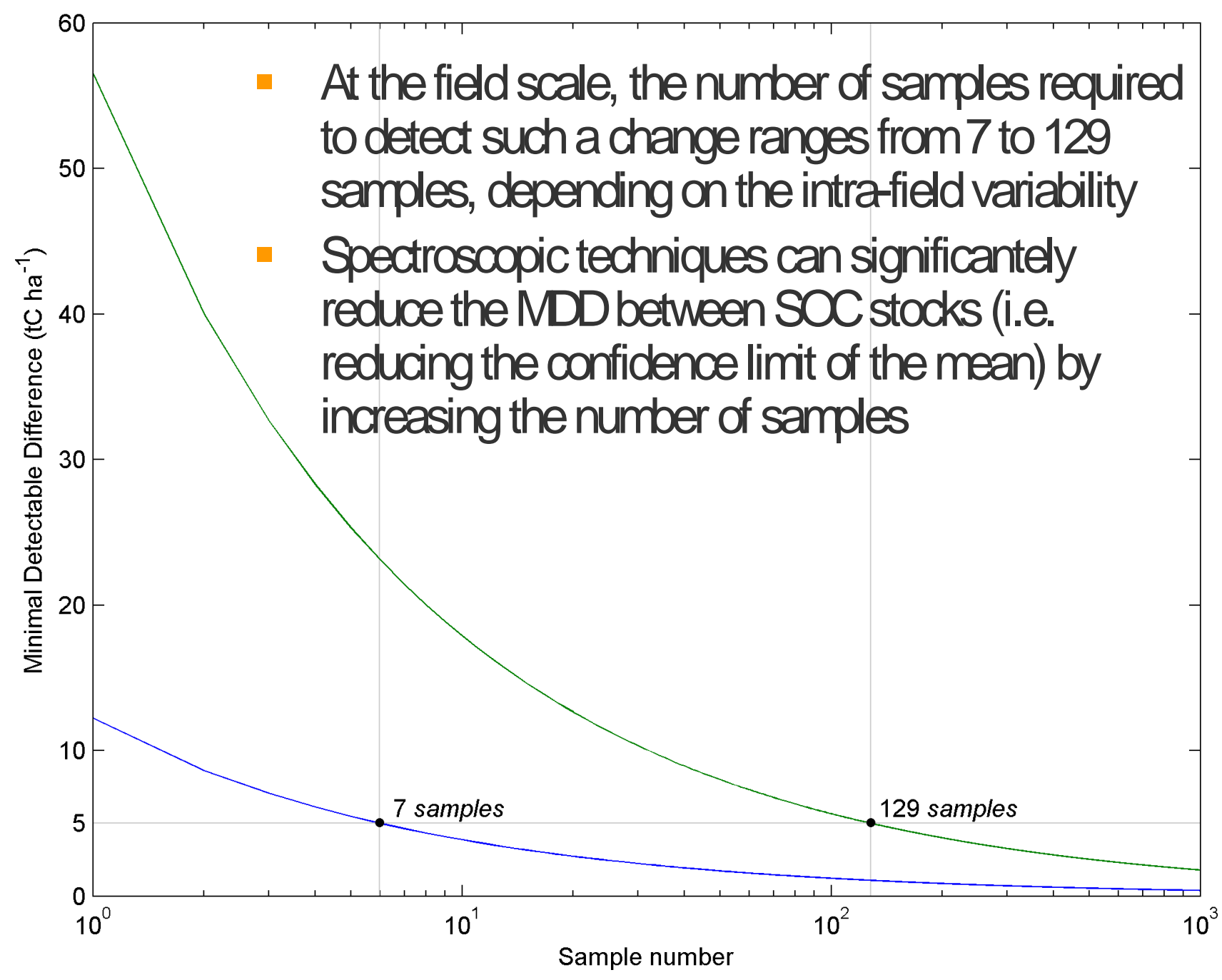

Hél i oSPI R, 25-26 Cot obr e2007 - Grenobl e, Fr ance 
$\square \square$ Soil Mapping

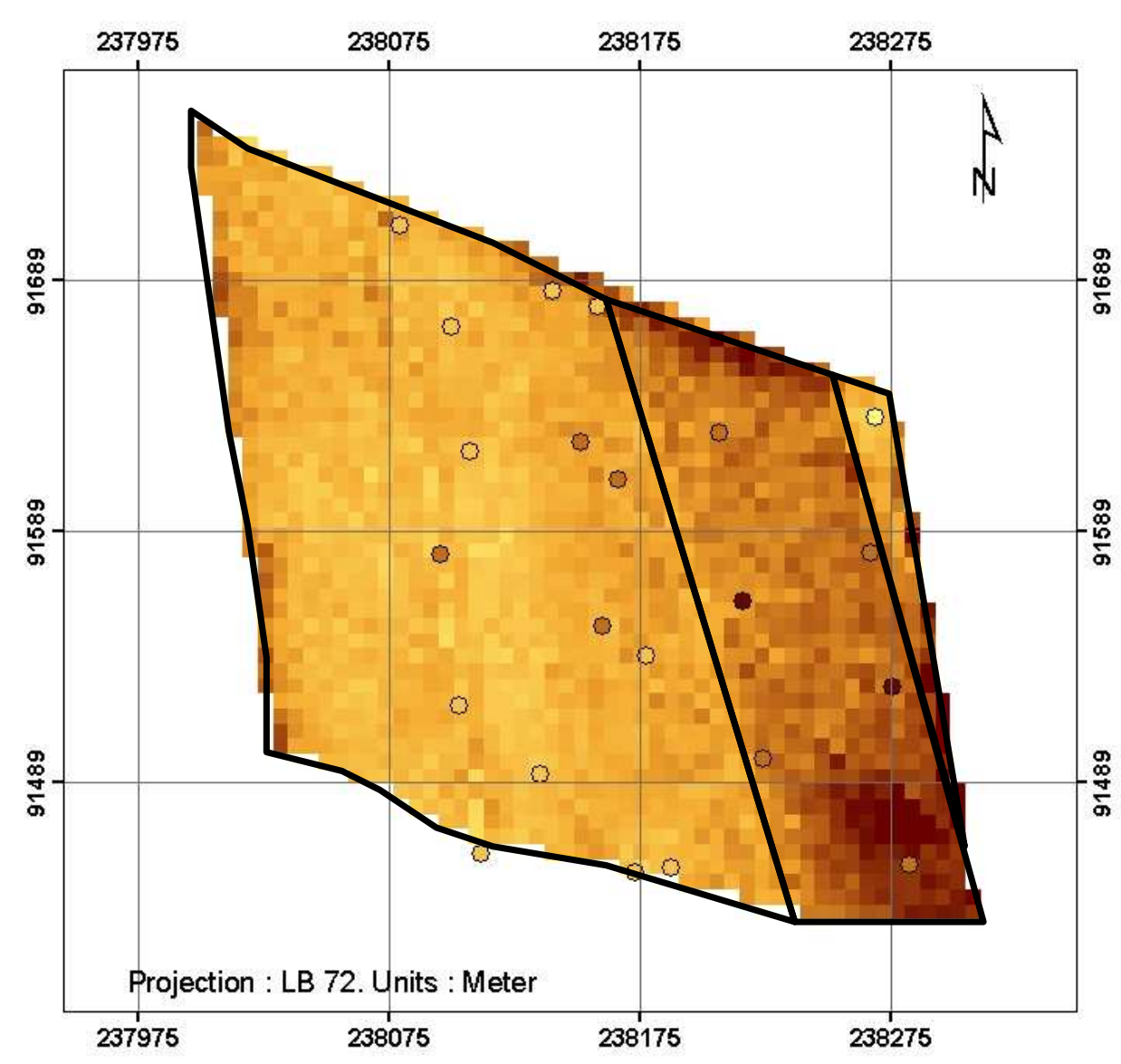

CASI

Legend

$\%$ Carbon

High : 4.19

Low: 1.96 
- $\square$ Soil Mapping
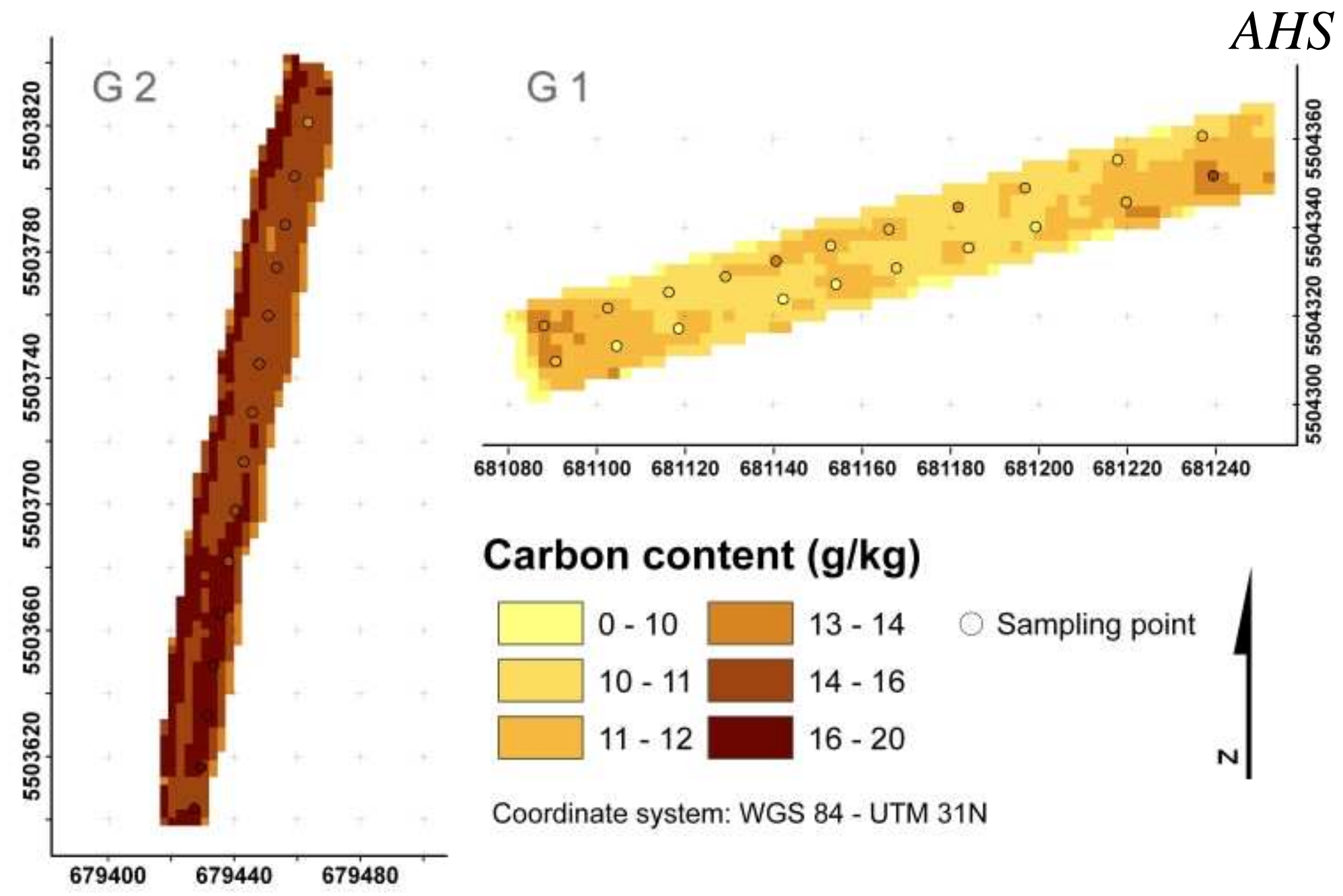

\section{Carbon content $(\mathbf{g} / \mathbf{k g})$}

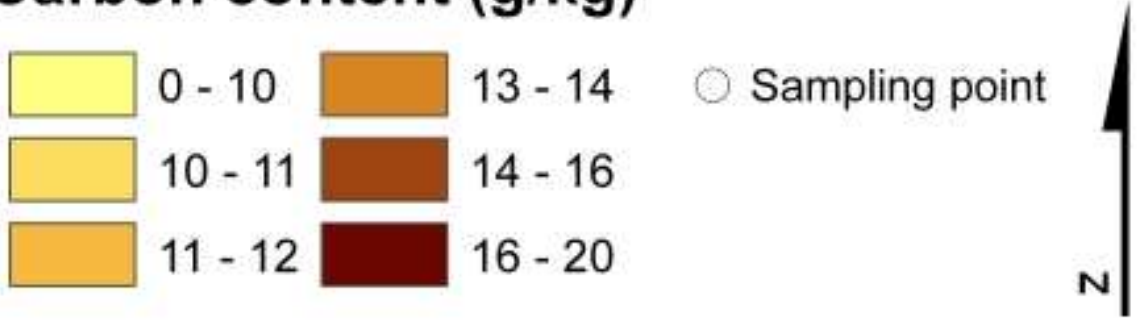

Coordinate system: WGS 84 - UTM 31N

Hél i oSPI R, 25-26 Cot obr e2007 - Grenobl e, Fr ance 
- $\square$ Condusion

- Conclusion

- Accuracies achieved by the ground measurements (Laboratory and Portable Spectroscopy) are comparable to the one of a standard analytical method (Walkley-Black) and they can thus be used for monitoring studies where their speed is a valuable advantage.

- Imaging spectroscopy, appears, for the time being, not able to predict SOC with an acceptable accuracy due to its low SNR and problem to achieve true spectral information. Nevertheless, the greater potential lies in this technique and more efforts have to be put in spectrum calibration 
Merci pour votre attention! 口 